\title{
Determinants of infant and young child feeding practices by mothers in two rural districts of Sindh, Pakistan: a cross-sectional survey
}

Gul Nawaz Khan', Shabina Ariff', Ubaidullah Khan², Atif Habib', Muhammad Umer', Zamir Suhag', Imtiaz Hussain', Zaid Bhatti ${ }^{1}$, Asmat Ullah¹, Ali Turab', Ali Ahmad Khan³ , Alba Cecilia Garzon³, Mohammad Imran Khan ${ }^{4}$ and Sajid Soofi ${ }^{*}$

\begin{abstract}
Background: Infant and young child feeding (IYCF) practices during the first two years of life are important for the growth and development of a child. The aim of this study was to assess IYCF practices and its associated factors in two rural districts of Pakistan.

Methods: A cross-sectional study was conducted in two rural districts of Sindh province, Pakistan as part of a stunting prevention project between May and August 2014. A standard questionnaire on IYCF practices recommended by World Health Organization was used to collect information from 2013 mothers who had a child aged between 0 and 23 months.

Results: Only 49\% of mothers initiated breastfeeding within one hour of birth. Thirty-seven percent of mothers exclusively breastfed their infants for six months. Seventy-percent mothers introduced complementary feeding at 6-8 months of age. Eighty-two percent of mothers continued breastfeeding for at least one year and 75\% for at least two years of age. IYCF practices were not significantly different for boys and girls in the study area. Being an employed mother (AOR 2.14; $95 \% \mathrm{Cl}$ $1.02,4.51$ ) was positively associated with the early initiation of breastfeeding. Children who were born at a health facility (AOR 0.65; 95\% Cl 0.50, 0.84) and were aged six to eleven months (AOR 0.70; $95 \% \mathrm{Cl} 0.54,0.90$ ) were less likely to be have an early initiation of breastfeeding. Mothers aged 25 to 29 years (AOR 1.83; 95\% Cl 1.05, 3.18), being literate (AOR 1.79; $95 \% \mathrm{Cl} 1.15,2.78$ ), and higher income (AOR 10.6; $95 \% \mathrm{Cl} 4.40,25.30$ ) were more likely to have an improved dietary diversity. Being an employed mother (AOR 2.18; 95\% Cl 1.77, 4.03) and higher income were more likely to have minimum acceptable diet (AOR 9.7; 95\% Cl 4.33, 21.71).
\end{abstract}

Conclusion: IYCF practices were below the acceptable level and associated with maternal age, maternal illiteracy, unemployment, and poor household wealth status. Emphasis should be given to improve maternal literacy and reduction in poverty to improve IYCF practices.

Keywords: Infant, Young, Child, Feeding, Practices, Factors, Pakistan

\footnotetext{
*Correspondence: sajid.soofi@aku.edu

'Department of Paediatrics and Child Health, The Aga Khan University,

Karachi, Pakistan

Full list of author information is available at the end of the article
}

(c) The Author(s). 2017 Open Access This article is distributed under the terms of the Creative Commons Attribution 4.0 International License (http://creativecommons.org/licenses/by/4.0/), which permits unrestricted use, distribution, and reproduction in any medium, provided you give appropriate credit to the original author(s) and the source, provide a link to the Creative Commons license, and indicate if changes were made. The Creative Commons Public Domain Dedication waiver (http://creativecommons.org/publicdomain/zero/1.0/) applies to the data made available in this article, unless otherwise stated. 


\section{Background}

In 1998, the executive board of the World Health Organization (WHO), called for the revitalization of the global commitment to appropriate infant and young child nutrition, and in particular breastfeeding and complementary feeding [1]. The first two years of the child's life provide a critical window of opportunity to ensure survival, growth and development through optimum infant and young child feeding (IYCF) practices [2]. Optimal breastfeeding practices, including the initiation of breastfeeding within one hour of birth, exclusive breastfeeding (EBF) for six months [3], and continuation of breastfeeding for up to two years and beyond, with age appropriate complementary feeding, all have great potential for reducing under five malnutrition and thereby affecting child mortality rate $[2,4,5]$.

The WHO therefore has recommended tracking IYCF indicators on the introduction of soft, solid or semi-solid foods, minimum dietary diversity, minimum meal frequency, and minimum acceptable diet during two years of age [6]. Early introduction of complementary feeding is a common cultural practice in South Asian countries including Pakistan [7-10], and the same counties contribute significantly to the high burden of under-nutrition in the region $[9,11]$. The Pakistan National Nutrition Survey (NNS) 2011 reported in Sindh province that $51 \%$ of mothers initiated breastfeeding within one hour after birth, $67 \%$ predominantly maintained breastfeeding, and $9.6 \%$ of children were exclusively breastfed up to six months [12]. Similarly, 3.2\% of children age 6-23 months of age were offered the minimum dietary diversity, $54.1 \%$ offered the minimum meal frequency, and 5.8\% were offered an acceptable diet [13].

Sociodemographic factors associated with EBF included maternal age, education [13-15], income and health facility births [16, 17]. The mother's formal education [18-20], and birth order of index child was significantly associated with early initiation of breastfeeding [20, 21].

Evidence suggests that maternal education is associated with timely introduction of complementary feeding, meal frequency, dietary diversity, and the practice of a minimum acceptable diet [22-25]. Moreover, household wealth status, geographical location, exposure to media, maternal age, and the utilization of antenatal and postnatal visits are associated with improved complementary feeding practices [22, 25-28]. Additional information is required to provide more evidence to monitor progress at the local level. This study was aimed to measure IYCF indicators and to identify factors associated with poor IYCF practices. The findings of this study will help policy makers to target behavior change strategies in mothers to enhance the IYCF practices in Pakistan.

\section{Methods}

\section{Study design}

A cross-sectional survey was conducted to collect data between May and August 2014. The survey was designed to provide IYCF and baseline indicators on a representative sample of households in the study area.

\section{Study setting}

This study was conducted in two districts of Thatta and Sujawal in Sindh, Pakistan. These districts are administratively subdivided into nine Talukas and 55 union councils (UCs) with a population of 1.5 million. More than $88 \%$ of the population in Thatta and Sujawal has access to improved sources of drinking water. Sixty eight percent have access to electricity and $31 \%$ of households own some agriculture land. Finished floors are present in $35 \%$ of households, roofing in $36 \%$ and walls in $40 \%$ of households [29].

\section{Study participants}

The study participants for this survey were the mothers of children aged less than two years who lived in the study area for more than six months. In the case of having two or more mothers with children under-two years of age in the household, we selected the one with younger child.

\section{Sample size}

Sample size for this study was calculated using comparison of two sequential surveys approach. This design was used to assess the impact of intervention over time as discussed in Micronutrient Initiative (MI) and Center for Disease Control (CDC) manual [30]. Sample size calculation considered the prevalence of stunting in Sindh at 55\% (NNS 2011) and design effect of 1.5. Total sample size was 2166 per survey to detect $10 \%$ difference in stunting. With a power of $80 \%$ and a significance level of $5 \%$, the sample size was inflated by $10 \%$ for non-response.

\section{Sampling methodology}

A two-staged cluster sampling technique was used to select households for interviews. In the first stage, the sample size was divided in 29 UCs using a Proportion to Population Size (PPS) design. In the second stage, the villages and households with children under-two years of age were randomly selected for interview on baseline and IYCF indicators.

\section{Data collection}

Sixteen data collectors, four team leaders, two desk editors and two field supervisors were trained and involved in baseline data collection. Senior faculty and staff belonging to the Department of Paediatrics and Child Health, Aga Khan University arranged the five day training. Three days were dedicated to didactic training of staff, one day was spent on field pilot testing and one day for a short refresher that included problems and irregularities found during the pilot testing. 
A standard questionnaire on IYCF practices recommended by WHO was used to collect information from mothers with children aged between 0 and 23 months. The information collected included IYCF practices and socioeconomic characteristics. The questionnaire was initially designed in English, with subsequent translation to Sindhi by a senior project team staff that was well versed in both languages. It was then translated back in English. An independent review of the questionnaire was done eventually to check for any inconsistencies.

\section{Definition of variables used in the study} Early initiation of breastfeeding

Children born in the last 24 months who received breast milk within one hour of birth.

\section{Exclusive breastfeeding}

Infants 0-5 months of age who received only breast milk and nothing else: no other milk, food, drink, not even water during the previous day.

\section{Continued breastfeeding at one year}

Children 12-15 months of age who received breast milk during the previous day.

\section{Introduction of solid, semi-solid or soft foods}

Infants 6-8 months of age who received solid, semi-solid or soft foods during the previous day.

\section{Minimum dietary diversity}

Children 6-23 months of age who received foods from four or more food groups during the previous day.

\section{Minimum meal frequency}

Breastfed and non-breastfed children 6-23 months of age who receive solid, semi-solid, or soft foods (but also including milk feeds for non-breastfed children) the minimum number of times or more during the previous day.

\section{Minimum acceptable diet}

Children 6-23 months of age who receive a minimum acceptable diet (apart from breast milk) during the previous day.

\section{Consumption of iron-rich or iron-fortified foods}

Children 6-23 months of age who received an iron-rich food or a food that was specially designed for infants and young children and was fortified with iron, or a food that was fortified in the home with a product that included iron during the previous day.

\section{Continued breastfeeding at two years}

Children 20-23 months of age who received breast milk during the previous day.

\section{Age-appropriate breastfeeding}

Infants $0-5$ months of age who received only breast milk during the previous day, and children 6-23 months of age who received breast milk, as well as solid, semi-solid or soft foods, during the previous day.

\section{Predominant breastfeeding under six months}

Infants $0-5$ months of age who received breast milk as the predominant source of nourishment during the previous day.

\section{Taluka}

Taluka or Tehsil is second administrative level after district in all provinces of Pakistan.

\section{Union council}

Union council is lowest administrative unit in Pakistan with a population between 25,000 to 70,000 .

\section{Statistical analysis}

Paper based data was entered on predefined data entry screens using Microsoft visual fox pro version 9.0. STATA version 12 was used for data analysis. Frequencies and percentages were calculated for categorical variables. Multivariable analysis was used for the impact of each variable by odds ratio with $95 \% \mathrm{CI}$ and $p$ - value $<0.05$ being considered statistically significant. Initiation of breastfeeding, $\mathrm{EFB}$, minimum dietary diversity, minimum acceptable diet and age appropriate breastfeeding were defined as binary variables. We tested bivariate analysis for factors associated with all outcome variables. The $p$ - value $<0.25$ in the bivariate was used for inclusion in the multivariable logistic regression model. Factors that were insignificant at the multivariable model were excluded after careful assessment of confounders. The final model was selected on the basis of theoretical and statistical significance of predictors. Clusters were adjusted to take sampling design into account.

Wealth indexes were based on the principal component analysis using household assets, household ownership status, materials used for the roof, floor and wall of the house, number of rooms, fuel for cooking, main source of drinking water and toilet facility. Wealth scores were divided into five parts to make wealth quintile: poorest, poor, middle, rich and richest [31].

\section{Results}

\section{Characteristics of study sample}

All mothers in the selected households consented to participate in the survey. A total of 2013 mother-child pairs were included for analysis. The mean age of mothers was 30 years ( $\mathrm{SD} \pm 0.25$ years) and mean age of children was 11 months (SD \pm 0.12 months). The majority of mothers $(87 \%)$ were illiterate. A very small proportion $(4 \%)$ 
of mothers was employed, while $96 \%$ were a homemaker. Sixty-two percent received 1-3 outpatient antenatal care visits with a primary care provider, while $20 \%$ didn't receive any antenatal care during their last pregnancy. Approximately $58 \%$ were health facility births. The gender proportion was almost equal (50.7\% and 49.3\%). Improved drinking water was available in $38 \%$ of the households. Forty-one percent of households were using improved toilet facilities. Four percent of households were severely food insecure, approximately half of households were moderately food insecure and $46 \%$ of households experienced none or light hunger (Table 1).

\section{Infant and young child feeding practices}

Table 2 presents infant and young child feeding practices in the study area. About half of mothers (49\%) initiated breastfeeding within one hour of birth. More than quarter (37\%) was exclusively breastfeeding up to six months, while $68 \%$ were predominantly breastfeeding under six months in the last $24 \mathrm{~h}$ preceding the survey. Seventypercent of mothers introduced solid, semi-solid or soft foods during six to eight months of age. Only $38 \%$ of children (6-23 months) received the minimum meal frequency, $10 \%$ received the recommended minimum dietary diversity, and $8 \%$ received the minimum acceptable diet in the last $24 \mathrm{~h}$ preceding the survey. Almost all children (99.9\%) were ever breastfed equally, both boys and girls. Eighty-two percent of mothers continued breastfeeding up to one year of age, while $75 \%$ continued up to two years of age. Age appropriate breastfeeding (0-23 months) was $78 \%$. Overall $12 \%$ of mothers used bottle feeding ( $14 \%$ for boys \& $10.4 \%$ for girls). Other IYCF practices for both genders were not remarkably different.

\section{Determinants of infant and young child feeding practices}

Table 3 presents determinants of infant and young child feeding practices in the study area. Being an employed mother (AOR 2.14; 95\% CI 1.02, 4.51) was positively associated with the early initiation of breastfeeding. Birthing at a health facility (AOR 0.65; 95\% CI 0.50, 0.84 ) and children aged 6-11 months (AOR 0.70; 95\% CI $0.54,0.90$ ) were negatively associated with early initiation of breastfeeding. Mothers who received between one to three antenatal care visits (AOR 0.55; 95\% CI $0.32,0.95$ ) and delivered at health facility (AOR 0.64; $95 \%$ CI $0.43,0.96$ ) were less likely to practice EBF under six months. Mothers aged 25-29 years were more likely to offer the minimum dietary diversity as compared to mothers of other age groups (AOR 1.83; 95\% CI 1.03, 3.26). Being an literate mother (AOR1.79; 95\% CI 1.15, 2.78), mothers aged between 25 and 29 years (AOR 1.83; $95 \%$ CI 1.05, 3.18), and a higher income (AOR 10.6; 95\% CI $4.40,25.30$ ) was positively associated with the minimum
Table 1 Characteristics of study sample

\begin{tabular}{|c|c|c|}
\hline Sociodemographic variables & $n=2013$ & \\
\hline Age of mothers & $n$ & $\%$ \\
\hline$<25$ Years & 312 & 15.5 \\
\hline 25-29 Years & 669 & 33.2 \\
\hline 30-35 Years & 633 & 31.4 \\
\hline $36+$ Years & 399 & 19.8 \\
\hline Mean \pm SD & $30.3 \pm 0.25$ & \\
\hline \multicolumn{3}{|l|}{ Educational status of mothers } \\
\hline Illiterate & 1747 & 86.8 \\
\hline Literate & 266 & 13.2 \\
\hline \multicolumn{3}{|l|}{ Occupation of mothers } \\
\hline Employed & 81 & 4.0 \\
\hline Housewife & 1932 & 96.0 \\
\hline \multicolumn{3}{|l|}{ ANC visits during last pregnancy } \\
\hline None & 411 & 20.4 \\
\hline $1-3$ visits & 1250 & 62.1 \\
\hline $4+$ visits & 352 & 17.5 \\
\hline \multicolumn{3}{|l|}{ Place of birth } \\
\hline At health facility & 1167 & 58.0 \\
\hline At home & 846 & 42.0 \\
\hline \multicolumn{3}{|l|}{ Age of children } \\
\hline $0-5$ months & 587 & 29.2 \\
\hline 6-11 months & 626 & 31.1 \\
\hline $12-23$ months & 800 & 39.7 \\
\hline Mean \pm SD & $10.6 \pm 0.12$ & \\
\hline \multicolumn{3}{|l|}{ Sex of child } \\
\hline Male & 1021 & 50.7 \\
\hline Female & 992 & 49.3 \\
\hline \multicolumn{3}{|l|}{ Source of drinking water } \\
\hline Improved & 767 & 38.1 \\
\hline Unimproved & 1246 & 61.9 \\
\hline \multicolumn{3}{|l|}{ Toilet facility } \\
\hline Improved & 834 & 41.4 \\
\hline Unimproved & 1179 & 58.6 \\
\hline \multicolumn{3}{|l|}{ Household food insecurity } \\
\hline None or light hunger (0-1 score) & 585 & 46.5 \\
\hline Moderate hunger (2-3 scores) & 623 & 49.5 \\
\hline Severe hunger (4-6 scores) & 50 & 4.0 \\
\hline \multicolumn{3}{|l|}{ Wealth Index } \\
\hline Poorest & 410 & 20.4 \\
\hline Poor & 391 & 19.4 \\
\hline Middle & 402 & 20.0 \\
\hline Rich & 403 & 20.0 \\
\hline Richest & 407 & 20.2 \\
\hline
\end{tabular}


Table 2 IYCF practices for the children in the study sample

\begin{tabular}{|c|c|c|c|c|}
\hline IYCF Practices & Overalln (\%) & Boysn (\%) & Girlsn (\%) & $p$-value \\
\hline Early initiation of breastfeeding within $1 \mathrm{~h}$ & $963(48.8)$ & $480(47.9)$ & $483(49.7)$ & 0.351 \\
\hline Exclusive breastfeeding under 6 months & $217(37.0)$ & $105(37.1)$ & $112(36.8)$ & 0.942 \\
\hline Continued breastfeeding at 1 year & $236(82.5)$ & $117(79.1)$ & $119(86.2)$ & 0.056 \\
\hline Introduction to solid, semi-solid or soft foods (6-8 months) & $229(70.0)$ & $118(69.0)$ & $111(71.2)$ & 0.709 \\
\hline Minimum dietary diversity (6-23 months) & $142(9.9)$ & $70(9.5)$ & $72(10.5)$ & 0.653 \\
\hline Minimum meal frequency (6-23 months) & $545(38.2)$ & $275(37.3)$ & $270(39.2)$ & 0.389 \\
\hline Minimum acceptable diet (6-23 months) & $112(7.9)$ & $53(7.2)$ & $59(8.6)$ & 0.414 \\
\hline Consumption of iron-rich or iron-fortified foods & $360(25.3)$ & $178(24.1)$ & $182(26.5)$ & 0.297 \\
\hline Children ever breastfed & 1985 (99.9) & $1006(99.9)$ & $979(99.9)$ & 0.589 \\
\hline Continued breastfeeding at 2 years & $133(74.7)$ & $72(74.2)$ & $61(75.3)$ & 0.875 \\
\hline Age-appropriate breastfeeding & $1543(77.7)$ & $768(76.3)$ & $775(79.2)$ & 0.205 \\
\hline Predominant breastfeeding under 6 months & $398(67.8)$ & $191(67.5)$ & $207(68.1)$ & 0.861 \\
\hline Bottle feeding & $243(12.3)$ & $142(14.1)$ & $101(10.4)$ & 0.015 \\
\hline
\end{tabular}

dietary diversity. Children aged six to eleven months (AOR 0.46 ; $95 \%$ CI $0.30,0.70$ ) were less likely to receive the minimum dietary diversity as compared to other children. It was found that mothers who were employed (AOR 2.18; 95\% CI 1.77, 4.03), and belonged to richest wealth quintiles (AOR 9.7; 95\% CI 4.33, 21.71) were more likely to provide the minimum acceptable diet to their children in the last $24 \mathrm{~h}$ than their counterparts. Children aged six and eleven months (AOR 0.50; 95\% CI 0.31, 0.79) were less likely to receive the minimum acceptable diet as compared to other children. Mothers aged between 30 and 35 years (AOR 1.59; $95 \%$ CI $1.11,2.26)$ were more likely to practice age appropriate breastfeeding as compared to other mothers. Children under six months (AOR 3.28; 95\% CI 2.11, 5.09) were more likely to receive age appropriate breastfeeding as compared to older children. The middle (AOR 0.51; $95 \% \mathrm{CI} 0.36,0.72$ ) and richest wealth quintiles (AOR $0.50 ; 95 \%$ CI $0.32,0.77$ ) were less likely to receive age appropriate breastfeeding compared to other wealth quintiles.

\section{Discussion}

The primary objective of this study was to assess IYCF practices and to identify potential determinants of the persistent low rates of IYCF practices in two rural districts of Sindh, Pakistan. Our results revealed that the IYCF practices were suboptimal. Only about half of mothers in our study reported that they initiated breastfeeding within one hour of birth. The prevalence of EBF and predominant breastfeeding was (37\% and 68\%), higher than that reported (29\% and 56\%) in Multiple Indicator Cluster Survey (MICS) Sindh 2014 [29], and a study conducted in Gilgit Pakistan [32]. This may be attributed to the difference in sampling strategies. The prevalence of EBF in our study was similar with the national rates reported in PDHS 2006-07 [33], 2012-13 [31] and in studies conducted in developing countries [34, 35].

Almost all (99.9\%) of mothers in our study had ever practiced breastfeeding which is almost similar to the recent Sindh provincial rates [31] and Dera Ghazi Khan in Pakistan [36]. Similar studies conducted in Ethiopia and Nepal [37-39] show comparative results. Seventypercent mothers introduced solid, semi-solid or soft foods during six to eight months of age and this high frequency is similar with Sindh provincial rates reported in MICS 2014 report [29], and studies in Nigeria [40, 41].

The proportion of infants receiving recommended minimum dietary diversity (10\%), minimum meal frequency (38\%) and minimum acceptable diet (8\%) was much lower in our study setting. A multi-country study conducted in five South Asian countries, including Pakistan, reported children aged 6-23 months received the minimum dietary diversity that ranged from a minimum of $15 \%$ in India to a maximum 71\% in Sri Lanka [27]. However, the proportion of infants receiving recommended minimum dietary diversity and minimum acceptable diet in our study setting was comparable with provincial rates [29] but lower than other studied conducted in developing countries [27, 40, 42]. This disparity may be related to the accessibility and availability to specific foods such as rice, wheat, potato and fish or the cultural dependency on food items that are deficient on important nutrients.

Evidence from Asian countries reveals that education of the mother is significantly associated with timely initiation of complementary foods and the minimum acceptable diet. Maternal education was also positively associated with infant feeding in other studies [22, 24, 43] but our study only showed association with minimum dietary diversity 


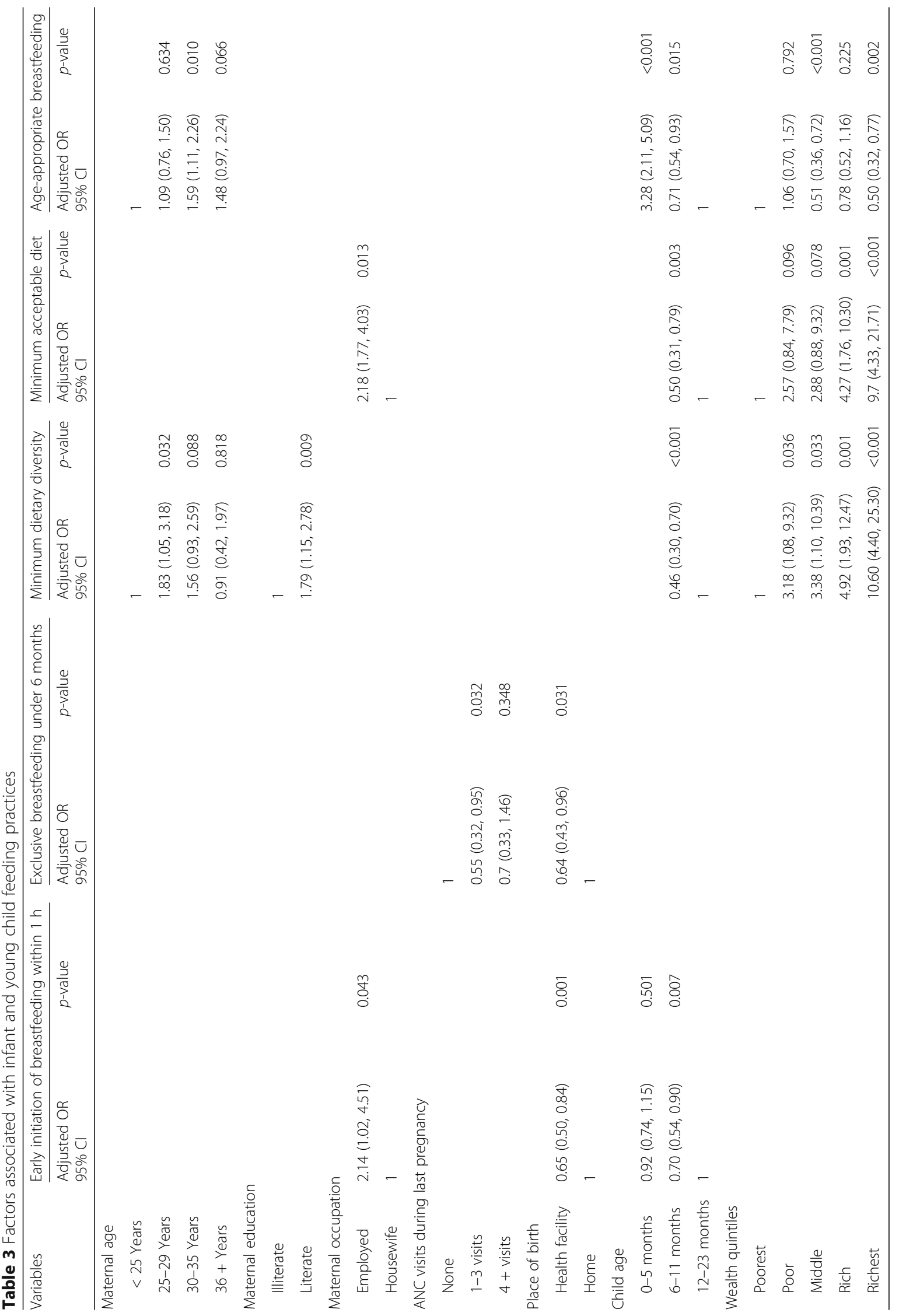


(AOR 1.79; 95\% CI 1.15, 2.78). This may be a reflection of our poor education system that does not provide an adequate and quality education about nutrition.

We found a significant association of a minimum dietary diversity (AOR 10.6; 95\% CI 4.40, 25.30), the minimum acceptable diet (AOR 9.70; 95\% CI 4.33, 21.71) and age appropriate breastfeeding (AOR 0.50; 95\% CI 0.32, 0.77) with the richest wealth quintiles. Our study is one of the few studies conducted in rural districts of Sindh that allowed the WHO guidelines on data collection for assessing IYCF indicators.

The study had some important limitations. To begin with, we cannot generalize it to every rural setting due to the small sample size. Moreover, due to the crosssectional study design, conclusions on the cause-effect relationship cannot be drawn. We were also not able to include the effect of seasonal variation and cultural practices on food availability and food consumption patterns. However it does provide a critical insight to the IYCF practices and some of the indicators that policy makers can focus upon.

\section{Conclusions}

The findings of our study reveal that the current IYCF practices are poor and significantly associated with maternal age, maternal illiteracy, unemployment, and poor household wealth status. Thus, emphasis should be given to improve maternal education status and employment for mothers. Moreover, special attention should be given to mothers with poor socioeconomic status to improve IYCF practices. Further research is recommended to investigate the potential factors associated with child feeding practices and interventions, to improve IYCF indicators in children under-two years of age.

\section{Abbreviations}

CDC: Center for Disease Control; ERC: Ethical Review Committee; IYCF: Infant and Young Child Feeding; MICS: Multiple Indicator Cluster Survey; NBC: National Bio-Ethics Committee; NNS: National Nutrition Survey; PPS: Proportion to Population Size; UC: Union Council; WHO: World Health Organization

\section{Acknowledgments \\ Authors would like to acknowledge all staff of the study for their hard work and support provided by National Programme, Government of Sindh. We would like to thank for the contribution of Yaqub Wasan, Mushtaque Dero, Imran Ahmed, Amjad Hussain, Ejaz Channa, Mir Asghar Ali and Salim Charania during the study period.}

\section{Funding}

This study was financially supported by World Food Programme (WFP), Pakistan.

\section{Availability of data and materials}

Data will be available upon request to corresponding author.

\section{Authors' contributions}

SS, SA, GNK and AH participated in the conceptualization and design of the study. GNK involved in monitoring of data collection, participated in analysis and preparation of the manuscript. ZB participated in analysis. SS, SA, UK, AH, $\mathrm{MU}, \mathrm{ZS}, \mathrm{AU}, \mathrm{AT}, \mathrm{IH}, \mathrm{AAK}, \mathrm{ACG}$ and IK participated in preparation and review of the manuscript. All authors read and approved the final manuscript.

\section{Ethics approval and consent to participate}

The ethical approval was received from Ethical Review Committee (ERC) of Aga Khan University and National Bio-Ethics Committee (NBC) of Pakistan. Informed written consent was obtained from parents of each child to participate in the study and all the data was kept confidential.

\section{Consent for publication}

Not applicable.

\section{Competing interests}

All authors declare that they have no competing interests.

\section{Publisher's Note}

Springer Nature remains neutral with regard to jurisdictional claims in published maps and institutional affiliations.

\section{Author details}

${ }^{1}$ Department of Paediatrics and Child Health, The Aga Khan University, Karachi, Pakistan. ${ }^{2}$ Department of Paediatrics, King Edward Medical University, Lahore, Pakistan. ${ }^{3}$ World Food Programme, Islamabad, Pakistan. ${ }^{4}$ Center of Excellence in Women and Child Health, The Aga Khan University, Karachi, Pakistan.

Received: 15 March 2017 Accepted: 10 September 2017 Published online: 16 September 2017

References

1. WHO/UNICEF. Global strategy for infant and young child feeding. Geneva, World Health Organization, 2003. http://apps.who.int/iris/bitstream/10665/ 42590/1/9241562218.pdf

2. Black RE, Allen LH, Bhutta ZA, Caulfield LE, de Onis M, Ezzati M, et al. Maternal and child undernutrition: global and regional exposures and health consequences. Lancet. 2008:371:243-60.

3. WHO: Global strategy for infant and young child feeding, the optimal duration of exclusive breastfeeding, Provisional agenda item 13.1. 2001. [http://apps.who.int/gb/archive/pdf_files/WHA54/ea54id4.pdf].

4. Jones G, Steketee RW, Black RE, Bhutta ZA, Morris SS. How many child deaths can we prevent this year? Lancet. 2003;362:65-71.

5. Edmond KM, Zandoh C, Quigley MA, Amenga-Etego S, Owusu-Agyei S, Kirkwood BR. Delayed breastfeeding initiation increases risk of neonatal mortality. Pediatrics. 2006;117(3):380-6.

6. World Health Organization. Indicators for assessing infant and young child feeding practices Part 1 Definitions. Washington: WHO Press. 2007.

7. Chandrashekhar TS, Joshi HS, Binu V, Shankar PR, Rana MS, Ramachandran $U$. Breast-feeding initiation and determinants of exclusive breast-feeding-a questionnaire survey in an urban population of western Nepal. Public Health Nutr. 2007;10:192-7

8. Faruque AS, Ahmed AM, Ahmed T, Islam MM, Hossain MI, Roy SK, et al. Nutrition: basis for healthy children and mothers in Bangladesh. J Health Popul Nutr. 2008;26:325

9. Hazir T, Senarath U, Agho K, Akram DS, Kazmi N, Abbasi S, et al. Determinants of inappropriate timing of introducing solid, semi-solid or soft food to infants in Pakistan: secondary data analysis of demographic and health survey 2006-2007. Matern Child Nutr. 2012;8:78-88.

10. Subba SH, Chandrashekhar TS, Binu VS, Joshi HS, Rana MS, Dixit SB. Infant feeding practices of mothers in an urban area in Nepal. Kathmandu Univ Med J. 2007:5:42-7.

11. Deolalikar AB. Poverty and child malnutrition in Bangladesh. J Dev Soc. 2005:21:55-90

12. National Nutrition Survey 2011. Planning commission, Planning \& Development Division, Government of Pakistan 2011.

13. Maonga AR, Mahande MJ, Damian DJ, Msuya SE. Factors affecting exclusive breastfeeding among women in Muheza District Tanga northeastern Tanzania: a mixed method community based study. Matern Child Health J. 2016:20:77-87.

14. Asemahagn MA. Determinants of exclusive breastfeeding practices among mothers in Azezo district Northwest Ethiopia. Int Breastfeed J. 2016;11:22.

15. Diji AK, Bam V, Asante E, Lomotey AY, Yeboah S, Owusu HA. Challenges and predictors of exclusive breastfeeding among mothers attending the child welfare clinic at a regional hospital in Ghana: a descriptive cross-sectional study. Int Breastfeed J. 2017;12:13. 
16. Gladzah N. Challenges of exclusive breastfeeding among female health workers in two hospitals in Accra. 2013. http://ugspace.ug.edu.gh/handle/ $123456789 / 5863$

17. Aidam BA, Perez-Escamilla R, Lartey A, Aidam J. Factors associated with exclusive breastfeeding in Accra, Ghana. Eur J Clin Nutr. 2005;59:789-96.

18. Setegn T, Gerbaba M, Belachew T. Determinants of timely initiation of breastfeeding among mothers in goba woreda, South East Ethiopia: a cross sectional study. BioMed Central Public Health. 2011;11:217.

19. Shwetal B, Pooja P, Neha K, Amit D, Rahul P. Knowledge, attitude and practice of postnatal mothers for early initiation of breast feeding in the obstetric wards of a tertiary care hospital of Vadodara city. Natl J Community Med. 2012;3(2):305-9.

20. Liben ML, Yesuf EM. Determinants of early initiation of breastfeeding in Amibara district, Northeastern Ethiopia: a community based cross-sectional study. Int Breastfeed J. 2016;11:7.

21. Adhikari M, Khanal V, Karkee R, Gavidia T. Factors associated with early initiation of breastfeeding among Nepalese mothers: further analysis of Nepal demographic and health survey, 2011. Int Breastfeed J. 2014;9:21.

22. Khanal V, Sauer K, Zhao Y. Determinants of complementary feeding practices among Nepalese children aged 6-23 months: findings from demographic and health survey 2011. BMC Pediatr. 2013;13:131.

23. Kalanda BF, Verhoeff FH, Brabin B. Breast and complementary feeding practices in relation to morbidity and growth in Malawian infants. Eur J Clin Nutr. 2006:60:401-7.

24. Pandey S, Tiwari K, Senarath U, Agho KE, Dibley MJ. South Asia infant feeding research network. Determinants of infant and young child feeding practices in Nepal: secondary data analysis of demographic and health survey 2006. Food Nutr Bull. 2010;31:334-51.

25. Kabir I, Khanam M, Agho KE, Mihrshahi S, Dibley MJ, Roy SK. Determinants of inappropriate complementary feeding practices in infant and young children in Bangladesh: secondary data analysis of demographic health survey 2007. Matern Child Nutr. 2012;8:11-27.

26. Dibley MJ, Roy SK, Senarath U, Patel A, Tiwari K, Agho KE, et al. Acrosscountry comparisons of selected infant and young child feeding indicators and associated factors in four south Asian countries. Food Nutr Bull. 2010;31:366-79.

27. Senarath U, Agho KE, Akram DE, Godakandage SS, Hazir T, Jayawickrama H, et al. Comparisons of complementary feeding indicators and associated factors in children aged 6-23 months across five south Asian countries. Matern Child Nutr. 2012;8:89-106.

28. Senarath U, Godakandage SS, Jayawickrama H, Siriwardena I, Dibley MJ. Determinants of inappropriate complementary feeding practices in young children in Sri Lanka: secondary data analysis of demographic and health survey 2006-2007. Matern Child Nutr. 2012;8:60-77.

29. Sindh Bureau of Statistics and UNICEF; Sindh Multiple Indicator Cluster Survey 2014, Final Report. Karachi: Sindh Bureau of Statistics and UNICEF; 2015.

30. Gorstein J, Sullivan KM, Parvanta I, Begin F. Indicators and methods for cross-sectional surveys of vitamin and mineral status of populations. The Micronutrient Initiative (Ottawa) and the Centers for Disease Control and Prevention (Atlanta) 2007.

31. National Institute of Population Studies (NIPS), ICF International. Pakistan Demographic and Health Survey 2012-13. Islamabad, Calverton: NIPS and ICF International. 2013.

32. Khan GN, Memon ZA, Bhutta ZA. A cross sectional study of newborn care practices in Gilgit, Pakistan. J Neonatal Perinatal Med. 2013;6:69-76.

33. National Institute of Population Studies (NIPS), Islamabad, Pakistan. Pakistan Demographic and Health Survey 2006-07. Maryland: Measure DHS, Macro International Calverton; 2007.

34. Vitta BS, Benjamin M, Pries AM, Champeny M, Zehner E, Huffman SL. Infant and young child feeding practices among children under 2 years of age and maternal exposure to infant and young child feeding messages and promotions in dares salaam, Tanzania. Matern Child Nutr. 2016;12(2):77-90.

35. Jino GB, Munyanshongone C, Birungi F. Knowledge, attitude and practice of exclusive breast-feeding of infants aged 0-6 months by urban refugee women in Kingali. Rwanda Med J. 2013;70:7-10.

36. Khan MA, Qureshi Z, Khan KA, Gill FN. Patterns and determinants of breast feeding among mother infant pairs in Dera ghazi khan, Pakistan. J Ayub Med Coll Abbottabad. 2016;28(4):750-4.

37. Setegn T, Belachew T, Gerbaba M, Deribe K, Deribew A, Biadgilign S. Factors associated with exclusive breastfeeding practices among mothers in Goba district, south east Ethiopia: a cross-sectional study. Int Breastfeed J. 2012;7:17.
38. Gultie T, Girum SG. Determinants of suboptimal breastfeeding practice in Debre Berhan town, Ethiopia: a cross sectional study. Int Breastfeed J. 2016;11:5.

39. Karkee R, Lee AH, Khanal A, Binns CW. Infant feeding information, attitudes and practices: a longitudinal survey in central Nepal. Int Breastfeed J. 2014:9:14.

40. Udoh EE, Amodu OK. Complementary feeding practices among mothers and nutritional status of infants in Akpabuyo area, Cross River State Nigeria. SpringerPlus. 2016;5:2073.

41. Awogbenja MD, Ugwuona FU. Feeding practices and nutritional status of under-five children in Nasarawa state, Nigeria. PAT. 2010;6(1):23-35.

42. Gautam KP, Adhikari M, Khatri RB, Devkota MD. Determinants of infant and young child feeding practices in Rupandehi, Nepal. BMC Res Notes. 2016;2:9-135.

43. Fein SB, Labiner-Wolfe J, Scanlon KS, Grummer-Strawn LM. Selected complementary feeding practices and their association with maternal education. Pediatrics. 2008;122:91-7.

\section{Submit your next manuscript to BioMed Central and we will help you at every step:}

- We accept pre-submission inquiries

- Our selector tool helps you to find the most relevant journal

- We provide round the clock customer support

- Convenient online submission

- Thorough peer review

- Inclusion in PubMed and all major indexing services

- Maximum visibility for your research

Submit your manuscript at www.biomedcentral.com/submit

) Biomed Central 